Southern Methodist University

SMU Scholar

9-2012

\title{
Studying the Effect of Laser Welding Parameters on the Quality of ZEK100 Magnesium Alloy Sheets in Lap Joint Configuration
}

\author{
Masoud Harooni \\ Southern Methodist University, mharooni@smu.edu \\ Fanrong Kong \\ Southern Methodist University, fkong@smu.edu \\ Blair Carlson \\ General Motors, blair.carlson@gm.com \\ Radovan Kovacevic \\ Southern Methodist University, Kovacevi@lyle.smu.edu
}

Follow this and additional works at: https://scholar.smu.edu/engineering_mechanical_research

Part of the Manufacturing Commons

\section{Recommended Citation}

M. Harooni, F. Kong, B. Carlson, R. Kovacevic, "Studying the Effect of Laser Welding Parameters on the Quality of Zek100 Magnesium Alloy Sheets in Lap Joint Configuration", ICALE012 Anaheim, Ca., pp. 539-548.

This document is brought to you for free and open access by the Mechanical Engineering at SMU Scholar. It has been accepted for inclusion in Mechanical Engineering Research by an authorized administrator of SMU Scholar. For more information, please visit http://digitalrepository.smu.edu. 


\title{
STUDYING THE EFFECT OF LASER WELDING PARAMETERS ON THE QUALITY OF ZEK100 MAGNESIUM ALLOY SHEETS IN LAP JOINT CONFIGURATION
}

\author{
1706
}

\author{
Masoud Harooni ${ }^{1}$, Fanrong Kong ${ }^{1}$, Blair Carlson ${ }^{2}$, Radovan Kovacevic ${ }^{1}$ \\ ${ }^{1}$ Center for Laser-aided Manufacturing, Lyle School of Engineering, Southern Methodist University, 3101 \\ Dyer Street, Dallas, TX 75205, USA \\ ${ }^{2} \mathrm{GM}$ : Research Center, Warren, MI, USA
}

\begin{abstract}
Magnesium has unique properties which makes it superior to many other metals. It has the best strengthto-weight ratio and the lowest density among structural metals. Therefore, it has been used in a variety of industries, including the automotive, aerospace, and electronics industries. However, because of magnesium metallurgical properties, fusion welding poses a significant challenge. Laser welding is one of the most efficient joining processes for welding magnesium alloys because of its low heat input. Low alloy magnesium ZEK100 has been used in the automotive industry; however, little research has been published on the welding of this alloy. In this study, a fiber laser is used to weld samples in a lap joint configuration in order to study the effect of process parameters on weld profile geometry including penetration depth and width on top surfaces and interfaces as well as its quality. Process parameters include laser power, scanning speed and gap between two sheets. Observations include weld bead surface quality, weld bead profile and micro-hardness. The obtained results show that each process parameter has a different effect on weld profile geometry and its quality. Then a regression model is used in order to obtain the geometry of the weld bead based on different process parameters. The performance evaluation of the regression model reveals that a wellrelated model is established.
\end{abstract}

\section{Introduction}

Magnesium alloys have been widely used in different industries because of their properties such as their light weight, high strength-to-weight ratio, high heat and electrical conductivity, recyclability, and nontoxicity [1]. Because of these properties and its positive effect on energy savings and environmental protection, magnesium is called a "green engineering metal" [1]. This light metal is used in different industries like the automobile, aerospace and electronics industries primarily to reduce weight and save on energy [2]. It is a quarter of the weight of steel and a third lighter than aluminum [3]. Its production rate has increased worldwide in order to satisfy the growing demand [4]. Different welding processes such as friction stir welding [5], arc welding [6], laser welding [7], electron beam welding [8], and hybrid welding [9] are used for welding magnesium alloys. Among these processes, laser welding is preferred because of its low heat input which results in less residual stress, a small heat affected zone (HAZ), deep penetration, a high welding speed, and ease of automation [3,10,11].

Different process parameters affect the quality and the geometry of the weld joint. In laser welding, process parameters mainly include laser power, welding speed, focal position and shielding gas [1]. By controlling these process parameters, a satisfactory weld bead geometry and high quality can be achieved. Laser power and welding speed are two of the most important process parameters affecting the weld bead shape and quality through the heat input [1]. AlKazzaz et al. [11] investigated the effect of the welding speed and focal position on the weldability of ZE41AT5 magnesium alloy. They AZ31B magnesium alloy stated that by increasing the welding speed, a significant grain refinement occurred in the fusion zone due to a high cooling rate. Abderrazak et al. [12] studied the effect of three different process parameters - laser power, welding speed, and shielding gas - on the weld bead geometry of the AZ91 magnesium alloy. They reported that by choosing proper process parameters, a satisfactory weld could be produced through the laser welding process. They also declared that shielding gas has less effect on the weld bead geometry than two other parameters. Hiraga et al. [13], evaluated the effect of shielding gas and laser wavelength on the laser welding of. They declared that welding with a Nd:YAG laser resulted in a better weld than welding with a $\mathrm{CO} 2$ laser. They also revealed that in the $\mathrm{CO} 2$ laser welding process, the shielding gas plays a more important role than in the case of the Nd:YAG laser welding process. Pan et al. [14] studied the optimization of parameters in laser welding of magnesium alloys using the Taguchi method. The process parameters included shielding gas, laser 
energy, welding speed, focal distance, pulse frequency, and pulse shape. They declared that shielding gas and laser power were the most important factors affecting the weld bead quality. In another study, Quan and his colleagues [15] investigated the effect of heat input on the tensile properties of the welded AZ31 magnesium alloy. They revealed that by increasing the heat input, the tensile strength of the weld joints increased at first and then decreased.

The main objective of the present study is to investigate the weldability of ZEK100 magnesium alloy and to optimize the laser process parameters in order to achieve a desirable weld bead shape and quality. The ZEK100 magnesium alloy contains zinc, rare earth elements and zirconium [16]. No studies have reported on the weldability of the laser welding of ZEK100 magnesium alloy to the best knowledge of the authors. A full factorial experiment is used to study the relative level of importance of the selected process variables as well as their relationship to the geometrical features of the weld bead. The effect of three main process parameters-laser power, welding speed, and the gap between two overlapped metal sheets - on weld bead geometry and quality are studied. The weld bead top surface and its crosssection are viewed with an optical microscope and the mechanical properties are checked with a microhardness test. Finally, a regression model is performed to predict the weld bead shape.

\section{Experimental Procedure}

A fiber laser integrated with a six axis KUKA robot is used to weld samples. The experimental setup is shown in Figure 1. The shielding gas is set up to protect the molten pool from oxidation and suppress laser induced plasma during the laser welding procedure. The argon supply nozzle is arranged in front of the laser head with an inclination angle of 30 degrees to the surface of the samples with a flow rate of 60 standard cubic feet per hour (SCFH).

Table1: Nominal chemical composition of the base metal

\begin{tabular}{|c|c|c|c|c|c|c|c|}
\hline Base metal & \multicolumn{6}{|c|}{ Chemical Composition } \\
\hline \multirow{2}{*}{ ZEK100 } & $\mathrm{Zn}$ & $\mathrm{Zr}$ & $\mathrm{Nd}$ & $\mathrm{Mn}$ & $\mathrm{La}$ & $\mathrm{Ce}$ & $\mathrm{Mg}$ \\
\cline { 2 - 7 } & 1.3 & 0.25 & 0.2 & 0.01 & $<0.01$ & Bal. \\
\hline
\end{tabular}

As-received ZEK100 magnesium alloy with a thickness of $1.5 \mathrm{~mm}$ (its chemical composition is shown in Table 1) is studied during these experiments. The coupons were cut out with an abrasive water-jet machine to dimensions of $64 \mathrm{~mm} \times 50 \mathrm{~mm}$ and then the surface was cleaned with acetone. The effect of three process parameters including laser power, welding speed and the gap size between two sheets with five levels were studied. The range of the process parameters (shown in Table 2) are chosen based on the preliminary bead on plate tests. The gap size is changed by inserting different spacers between two overlapped sheets at four points. By considering the levels of parameters, a total of 125 tests were carried out.

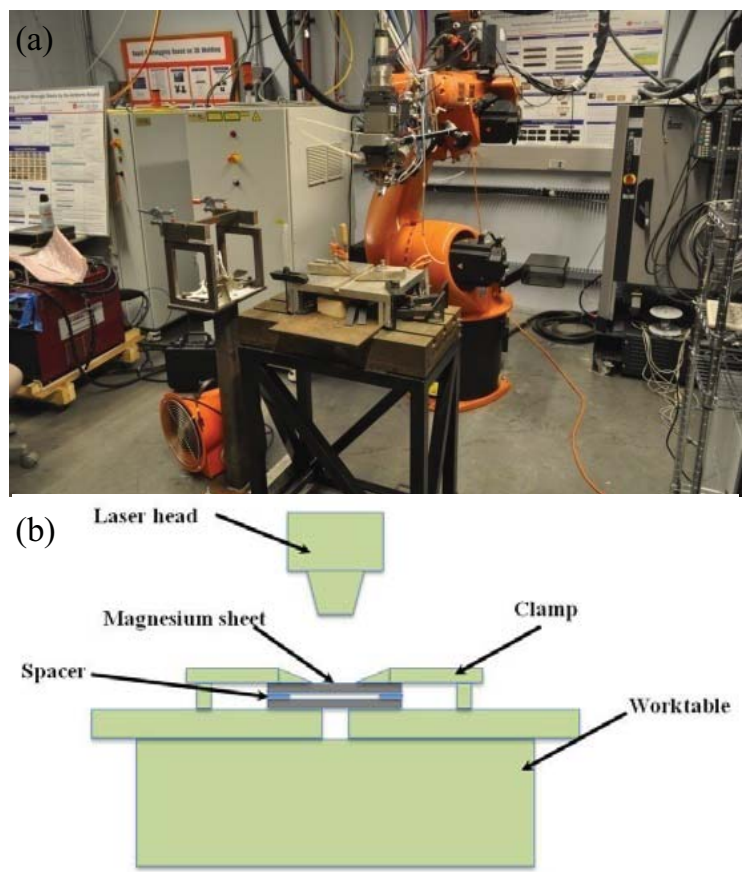

Figure 1: (a) Experiment setup and (b) A close-up of the weld setup

After welding, the weld quality is evaluated by observing the top surface of the weld bead. The samples for cross-sectional study are cut and then mounted for a standard polishing procedure. Then samples are etched with a $2 \%$ Nital solution. An optical microscope is employed to observe the weld bead geometry and quality. A micro-hardness test is carried out for 8 samples in order to observe the effect of the process parameters on the mechanical properties. In the micro-hardness test, for each process parameter variation, two other process parameters are held constant. The micro-hardness test is performed with a load of $200 \mathrm{~g}$ with a load time of $15 \mathrm{~s}$.

Table 2: Values of process parameters

\begin{tabular}{|c|c|c|c|c|c|}
\hline Parameters & \multicolumn{5}{|c|}{ Amounts } \\
\hline $\begin{array}{c}\text { Laser power } \\
(\mathrm{W})\end{array}$ & 1200 & 1400 & 1600 & 1800 & 2000 \\
\hline $\begin{array}{c}\text { Welding speed } \\
(\mathrm{mm} / \mathrm{s})\end{array}$ & 30 & 40 & 50 & 60 & 70 \\
\hline Gap (mm) & 0 & 0.05 & 0.1 & 0.15 & 0.2 \\
\hline
\end{tabular}




\section{Results and Discussion}

In evaluating the weldability of this magnesium alloy, the effect of process parameters on weld quality and its geometry is discussed. The top surface view, crosssectional view, and micro-hardness observations are used to judge the quality of the weld. The target for acceptable welds is good visual surface quality. After choosing acceptable welds based on surface quality, geometrical parameters such as penetration and width at the interface are studied under laser power, welding speed, and gap size. Finally, a regression model is performed in order to predict the effect of process parameters on the weld bead geometry.

\section{Effect of Process Parameters}

Welding Speed The top view of the welds obtained with different speeds is shown in Figure 2. The laser power and gap are kept at $1600 \mathrm{~W}$ and $0.1 \mathrm{~mm}$, respectively to show a typical case. The weld bead top surface observation is an important reflection of process stability [17]. As the results show, by increasing the welding speed, the weld quality is decreased and blowholes are formed in the weld metal. The viscosity of magnesium is extremely low and when the welding speed increases, it causes a sagging of the molten pool $[18,19]$. When the molten pool (with a low viscosity material) moves faster, it is characterized by turbulent flow. Furthermore, magnesium has low surface tension which results in violent fluid and a collapsing of the molten pool [1]. A better weld quality of magnesium is achieved with a lower welding speed. This conclusion is also supported by the findings reported in $[18,19]$.

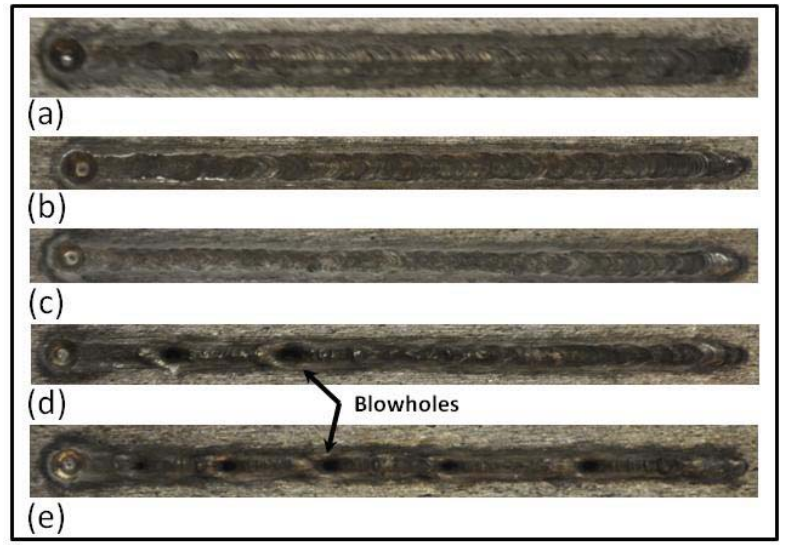

Figure 2: Top view of weld bead with $\mathrm{P}=1600 \mathrm{~W}$ and gap $=0.1 \mathrm{~mm}$ at different welding speeds (a) $30 \mathrm{~mm} / \mathrm{s}$, (b) $40 \mathrm{~mm} / \mathrm{s}$, (c) $50 \mathrm{~mm} / \mathrm{s}$, (d) $60 \mathrm{~mm} / \mathrm{s}$, and (e) 70 $\mathrm{mm} / \mathrm{s}$

The effect of the welding speed on the weld bead shape under the laser power of $1600 \mathrm{~W}$ and zero gap between metal sheets is shown in Figure 3. It is shown that by increasing the welding speed, the crosssectional area of the weld bead is decreased, resulting in partial penetration. This is related to the fact that by applying a higher welding speed, less heat input is delivered to the weld bead. Since the metal sheets are thin $(1.5 \mathrm{~mm}$ each), for most of the cases studied the full penetration is almost always achieved under the selected welding speed. At the selected laser power of $1600 \mathrm{~W}$ and zero gap, the highest welding speed that results in full penetration is $60 \mathrm{~mm} / \mathrm{s}$ (Figure $3 \mathrm{~d}$ ).

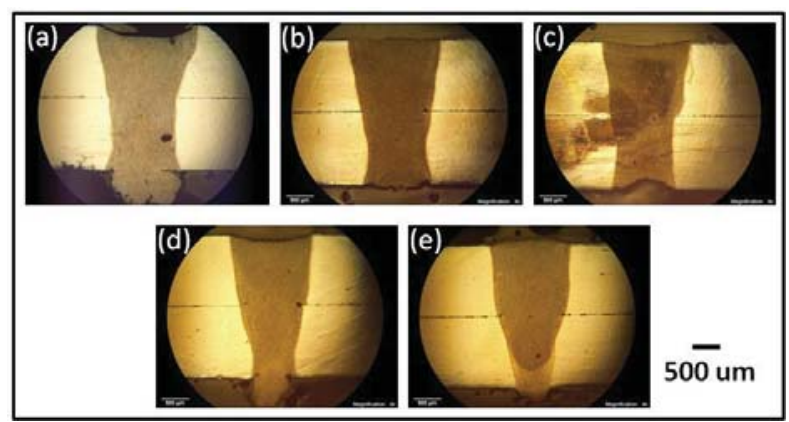

Figure 3: Effect of welding speed on bead width and penetration (laser power $=1600 \mathrm{~W}$, gap $=0 \mathrm{~mm}$ ) for different welding speeds (a) $\mathrm{V}=30 \mathrm{~mm} / \mathrm{s}$, (b) $\mathrm{V}=40$ $\mathrm{mm} / \mathrm{s},(\mathrm{c}) \mathrm{V}=50 \mathrm{~mm} / \mathrm{s}$, (d) $\mathrm{V}=60 \mathrm{~mm} / \mathrm{s}$, (e) $\mathrm{V}=70$ $\mathrm{mm} / \mathrm{s}$

The effect of the welding speed on the weld bead width on the top surface of two metal sheets of different gap sizes is shown in Figure 4. It is clear that by increasing the welding speed, the weld bead width at the top surface is decreased. This can be explained by the fact that the increase in the welding speed results in less heat input to the weld joint, resulting in a narrower weld bead as shown earlier in Figure 3. Also, it is evident that increasing the laser power increases the weld bead width on the top surface.

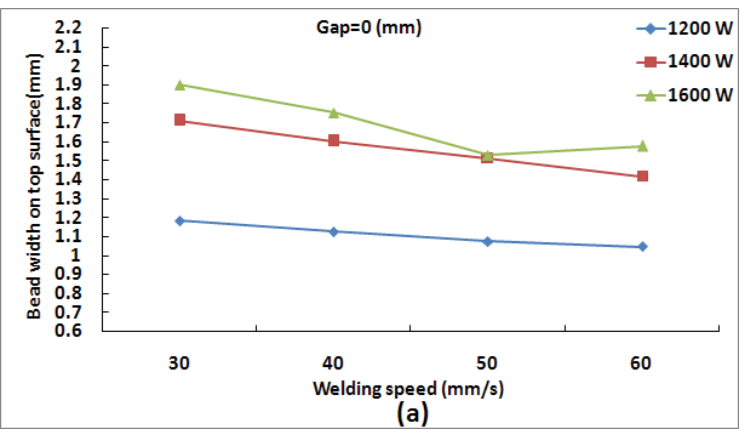




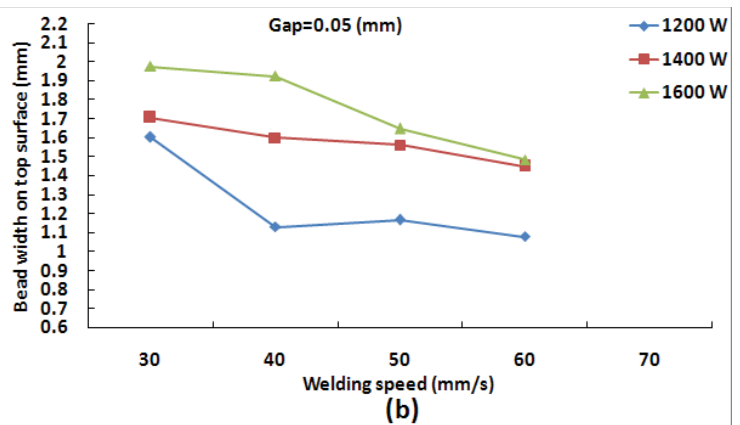

Figure 4: Effect of welding speed on weld bead width on top surface of two metal sheets for different gap size (a) $0 \mathrm{~mm}$, (b) $0.05 \mathrm{~mm}$

The effect of the welding speed on the weld bead width at the interface for different gap sizes of two metal sheets is shown in Figure 5. Note that by increasing the welding speed, the weld bead width at the interface of two metal sheets is decreased. This implies that by decreasing the welding speed, the area of weld pool increases. Also note that by increasing the gap (Figure 5b), the width at interface is decreased. This could be the result of the molten material tending to fill the gap at the interface resulting in a bulged weld bead.
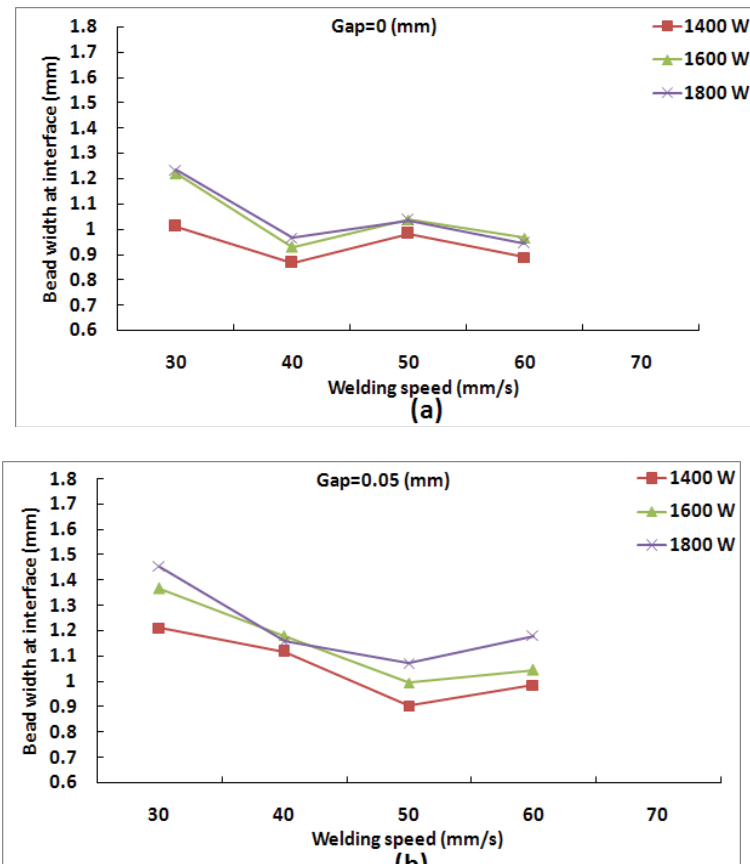

(b)

Figure 5: Effect of welding speed on weld bead width at interface under different gap sizes (a) $0 \mathrm{~mm}$, (b) 0.05 $\mathrm{mm}$

The micro-hardness of samples for different welding speeds, which is measured across the cross-section of the welds, is illustrated in Figure 6. The line along the measurement is placed $0.6 \mathrm{~mm}$ from the top surface of the weld. The results show that there is no significant variation in micro-hardness across the weld bead.

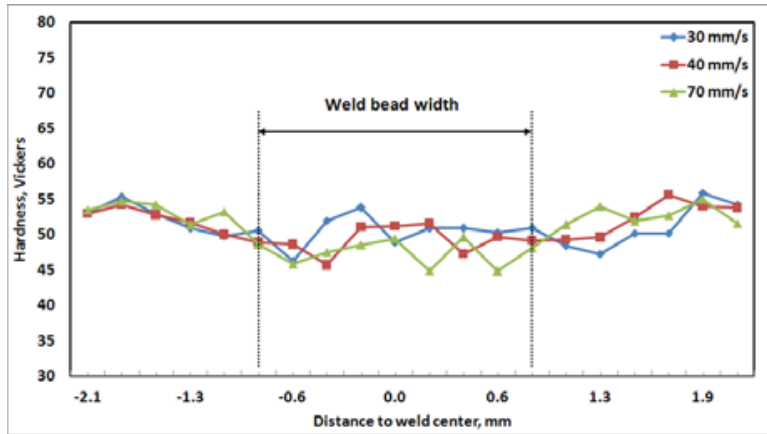

Figure 6: Micro-hardness distribution of typical welds at the laser power of $1600 \mathrm{~W}$ and zero gap

Laser Power The weld views of top surfaces obtained with different laser powers are shown in Figure 7. The welding speed and gap are $60 \mathrm{~mm} / \mathrm{s}$ and $0.1 \mathrm{~mm}$, respectively. It is clear that when the laser power is increased, blowholes and cavities appear in the weld bead. In Figure 7a, the weld top surface is smooth and there is no visible weld defect, which means the welding process is stable. However, increasing the laser power to $1400 \mathrm{~W}$ and above (Figures 7b-7e) blowholes and cavities are formed in the weld. Alloying elements with a low boiling point vaporize from the molten pool and there is no sufficient volume of liquid metal to fill the weld bead during its solidification. This phenomena cause cavities in the weld bead. Therefore, lower laser power is beneficial in welding magnesium sheets. This is also supported by the findings reported in [18-21]. Also, Figures 7a7e show that by increasing the laser power, the weld defects start to appear closer to the beginning of the weld (welding direction is right to left). This could be related to the heat buildup.

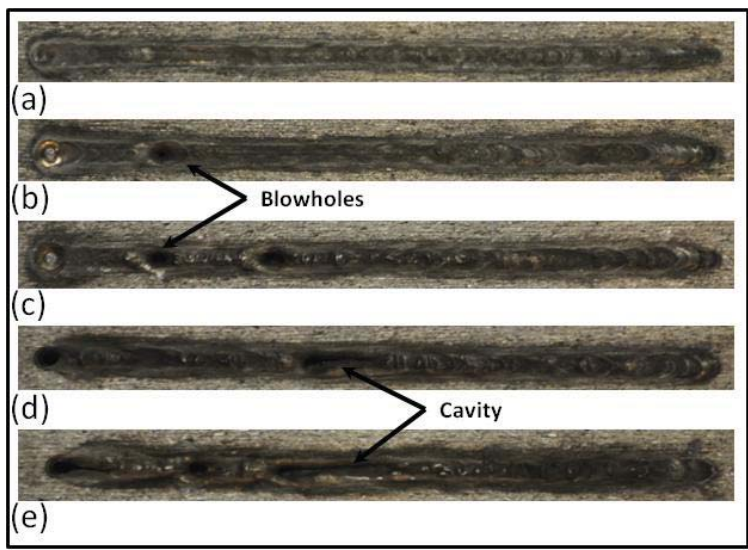

Figure 7: Top view of weld bead with welding speed of $60 \mathrm{~mm} / \mathrm{s}$ and gap $=0.1 \mathrm{~mm}$ and different laser power (a) $1200 \mathrm{~W}$, (b) $1400 \mathrm{~W}$, (c) $1600 \mathrm{~W}$, (d) $1800 \mathrm{~W}$, and (e) $2000 \mathrm{~W}$ 
The effect of laser power on the weld bead geometry for a zero gap and $60 \mathrm{~mm} / \mathrm{s}$ welding speed is presented in Figure 8. It is clearly shown that by increasing the laser power, the weld bead area is increased. In this case, the laser power of $1600 \mathrm{~W}$ (Figure 8c) is sufficient for achieving a fully penetrated weld bead. By increasing the laser power (Figures $8 \mathrm{~d}$ and $8 \mathrm{e}$ ) the molten pool geometry is changed from a conical to a cylindrical shape.

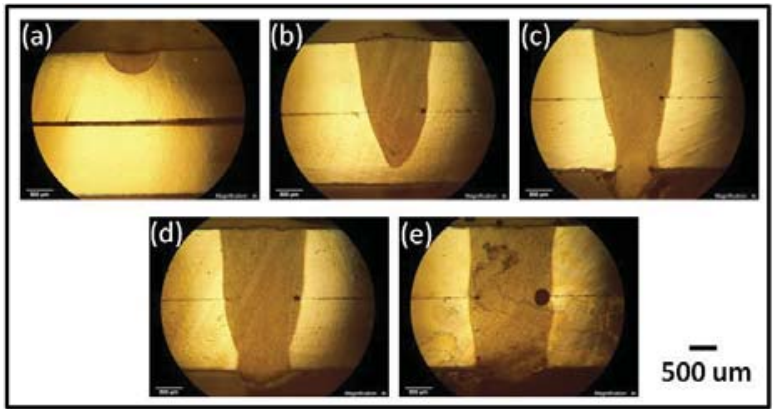

Figure 8: Effect of laser power on bead width and penetration (welding speed $=60 \mathrm{~mm} / \mathrm{s}$, gap $=0 \mathrm{~mm}$ ) for different laser powers (a) $1200 \mathrm{~W}$, (b) $1400 \mathrm{~W}$, (c) $1600 \mathrm{~W}$, (d) $1800 \mathrm{~W}$, (e) $2000 \mathrm{~W}$
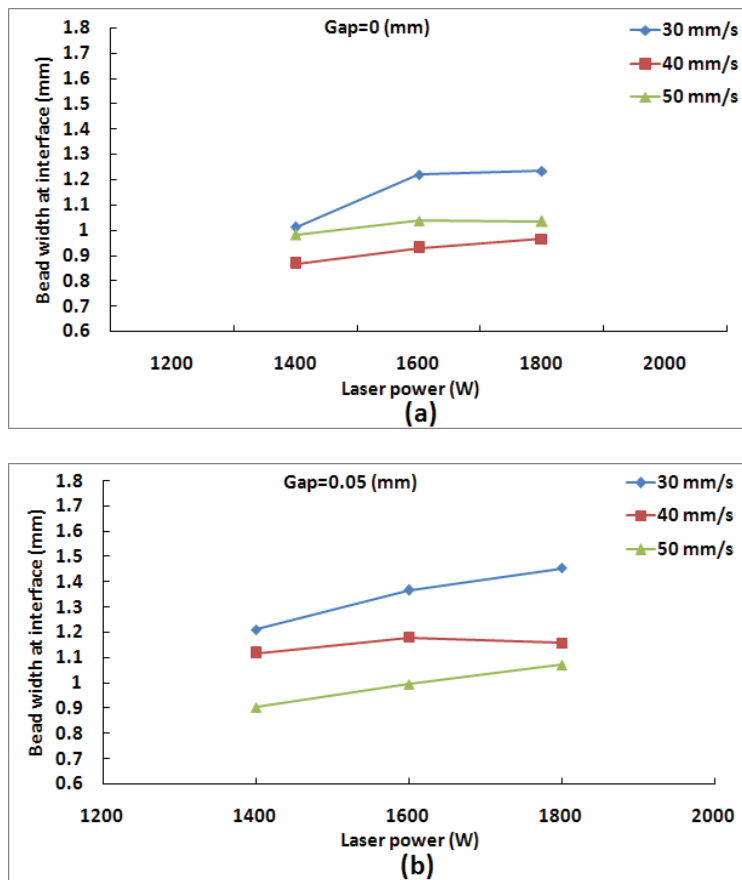

Figure 9: Effect of laser power on weld bead width at interface for different gap sizes (a) $0 \mathrm{~mm}$, (b) $0.05 \mathrm{~mm}$

Figure 9 shows the effect of laser power on the weld bead width at the interface. Note that by increasing the laser power at a constant speed, the width of the weld interface is increased. This means that the molten pool size is increased by increasing the laser power.
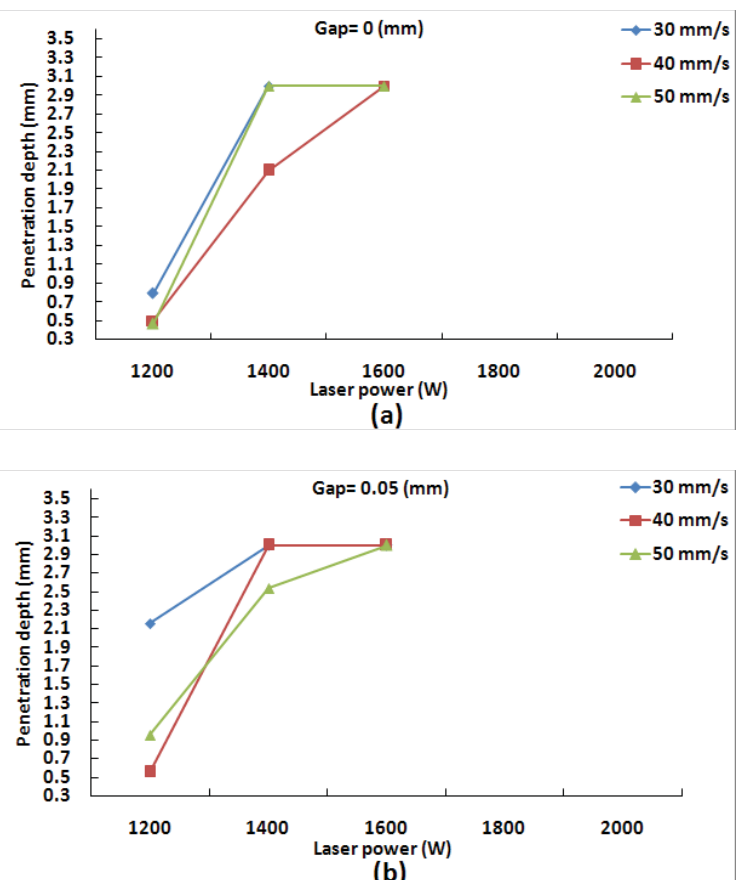

Figure 10: Effect of laser power on weld bead penetration depth for different gap size (a) $0 \mathrm{~mm}$, (b) $0.05 \mathrm{~mm}$

The effect of laser power on the weld depth is shown in Figure 10. The weld penetration is obviously deeper when the laser power is higher. Note that the increase in laser power causes an increase in the weld pool size due to higher heat input per weld length. However, in some instances, the increase of the welding speed, may cause an increase in the depth of weld bead. This was also reported by $[18,22]$.

Figure 11 shows the micro-hardness across the crosssection of weld for different laser powers in a zero gap lap joint configuration. There is no significant difference between these samples in micro-hardness. However, there is a small difference at the fusion zone related to the heat input changes.

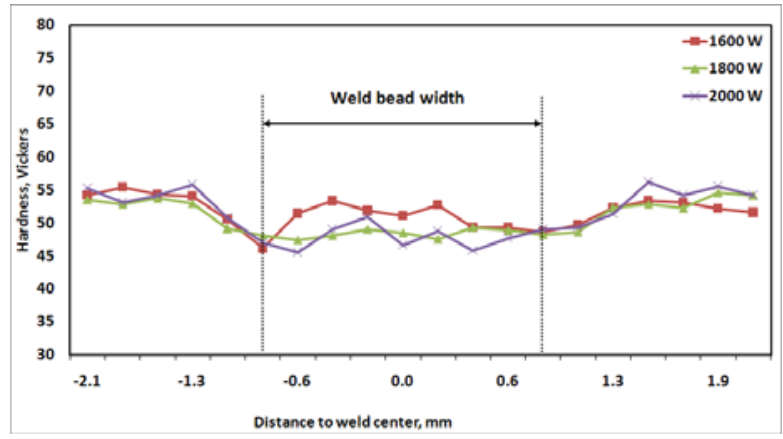

Figure 11: Micro-hardness distribution of typical welds at the welding speed of $50 \mathrm{~mm} / \mathrm{s}$ and zero gap 
Gap Size The top view of welded samples with different gap sizes is presented in Figure 12. The welding speed and laser power are $50 \mathrm{~mm} / \mathrm{s}$ and 1800 $\mathrm{W}$, respectively, for this case. It is clearly shown that a larger gap size increases the formation of cavities in the weld bead. As shown in Figures 12c-12e, the weld bead is discontinued intermittently, which shows that the molten pool is formed under unstable condition.

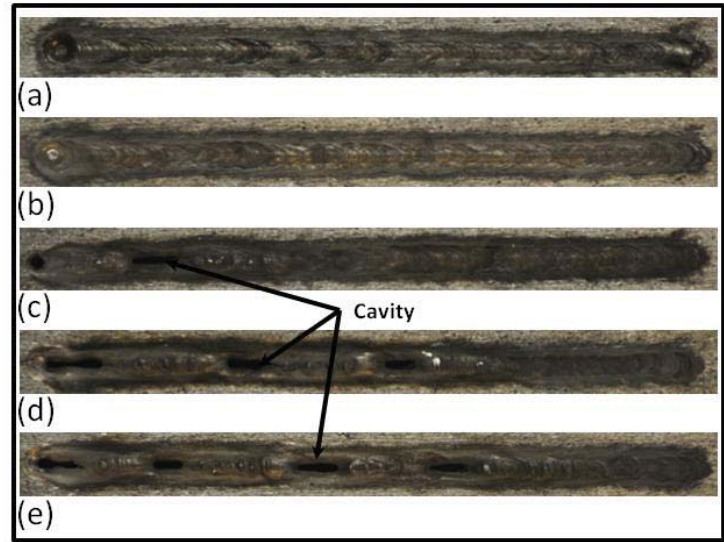

Figure 12: Top view of weld bead with laser power of $1800 \mathrm{~W}$ and welding speed of $50 \mathrm{~mm} / \mathrm{s}$ and different gaps (a) $0 \mathrm{~mm}$, (b) $0.05 \mathrm{~mm}$, (c) $0.1 \mathrm{~mm}$, (d) $0.15 \mathrm{~mm}$, and (e) $0.2 \mathrm{~mm}$

Figure 13 shows the effect of gap size on the weld bead geometry. Note that increasing the gap size increased the weld bead width at the interface, resulting in a bulged-shape weld bead. When the gap size is increased, liquid metal in the molten pool tends to fill the cavity at the interface which will result in expansion of the weld bead at the interface.

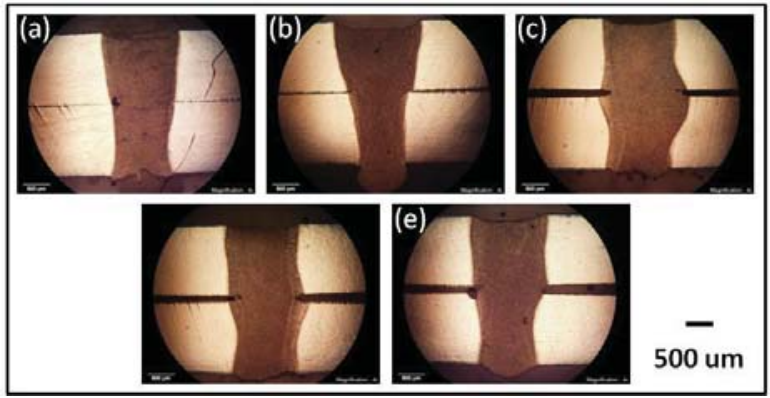

Figure 13: Effect of gap size on weld bead shape (welding speed $=50 \mathrm{~mm} / \mathrm{s}$, laser power $=1600 \mathrm{~W}$ ) for different gap size (a) $0 \mathrm{~mm}$, (b) $0.05 \mathrm{~mm}$, (c) $0.1 \mathrm{~mm}$, (d) $0.15 \mathrm{~mm}$, (e) $0.2 \mathrm{~mm}$

The effect of gap size on the weld bead width is shown in Figure 14. As it is shown the weld bead width is increases with the increase of the gap size. A comparison of Figures 13 and 14 implies that the molten metal in the weld bead tends to fill the cavity at the interface resulting in a bulged weld bead.
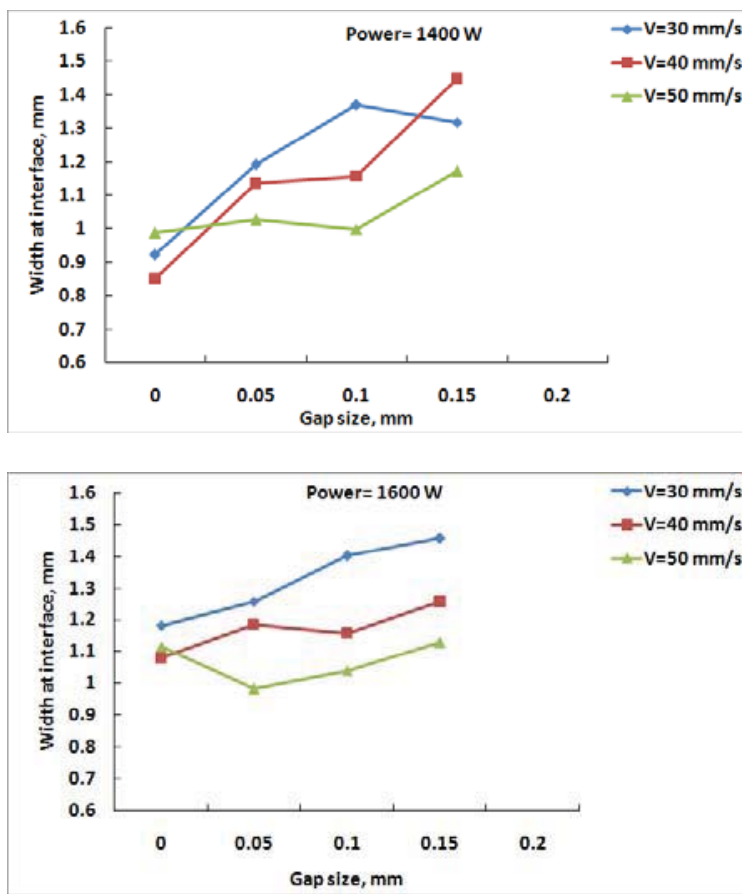

Figure 14: The effect of gap size on the weld bead width at interface for different powers (a) $\mathrm{P}=1400 \mathrm{~W}$, (b) $\mathrm{P}=1600 \mathrm{~W}$

In Figure 15, micro-hardness of samples with and without gap are compared. This figure shows there is no significant difference between the micro-hardness of two samples. However, the micro-hardness of the sample with a gap is slightly lower than the zero-gap sample in the fusion zone. When there is a gap between two metal sheets, there is no heat exchange between them at the interface; therefore, more heat is accumulated in the upper sheet where hardness is measured. This extra heat input might have resulted in coarsening the grains which finally resulted in less hardness.

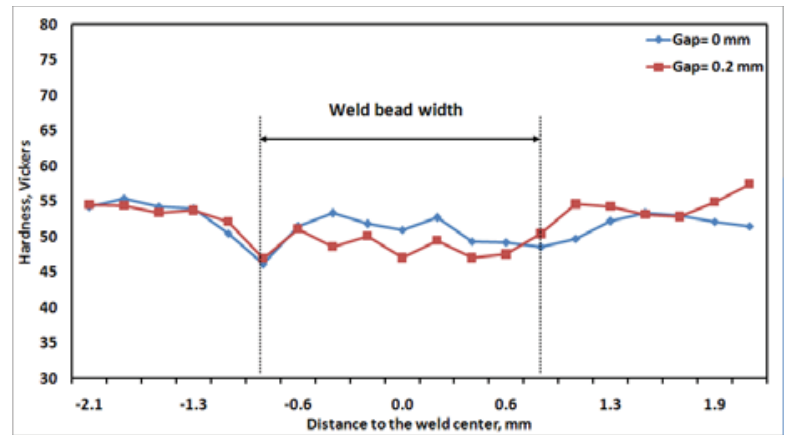

Figure 15: Micro-hardness distribution of typical welds at the welding speed of $50 \mathrm{~mm} / \mathrm{s}$ and $1600 \mathrm{~W}$ laser power

In Figure 16, the accepted process parameters based on weld bead surface quality for different gap sizes are 
presented. In Figure 16a, acceptable surface quality of the weld bead for the zero gap size is presented. It is clearly shown that the visual surface quality is acceptable for all ranges of powers and speeds. By comparing these figures (15a-15e), it is noted that when the gap size is increased, the non-acceptable range is increased. Based on this figure, the range of power, speed and gap size is defined. A laser power of $1600 \mathrm{~W}$ and below, a welding speed of $50 \mathrm{~mm} / \mathrm{s}$ and below and a gap size of $0.1 \mathrm{~mm}$ and below are considered in order to study the effect of these process parameters on the geometrical values of the weld bead.

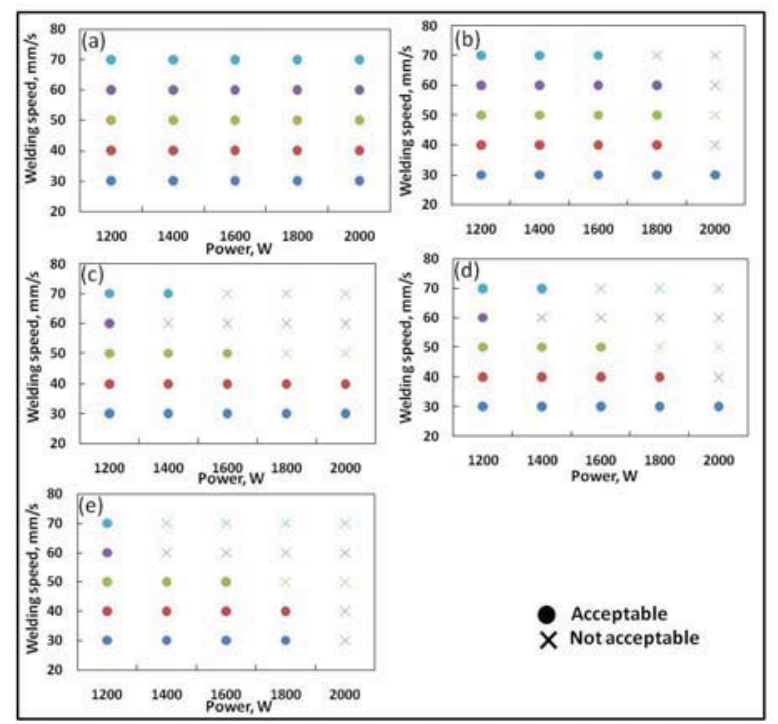

Figure 16: Acceptable process parameters for different gaps (a) gap $=0 \mathrm{~mm}$ (b) gap $=0.05 \mathrm{~mm}$, (c) gap $=0.1$ $\mathrm{mm}$, (d) gap $=0.15 \mathrm{~mm}$, and (e) gap $=0.2 \mathrm{~mm}$

\section{Process Modeling by Regression Analysis}

In order to estimate the effect of process parameters on weld bead geometry, a mathematical relation is developed for the weld depth and weld width at the interface. Based on the obtained results shown in Figure 16, a regression model is developed. The process parameters range between $1200-1600 \mathrm{~W}$ for the laser power, $30-50 \mathrm{~mm} / \mathrm{s}$ for the welding speed and $0-0.1 \mathrm{~mm}$ for the gap size. The response function may generally be written as:

$$
Y=f(P, V, G)
$$

where $\mathrm{Y}$ is the geometrical target, $\mathrm{P}$ is the laser power, $\mathrm{V}$ is the welding speed and, and $\mathrm{G}$ is the gap size between two metal sheets. There are different regression models available to estimate the relation between input and output variables. The most straightforward model is a linear regression model, however, it might not cover all the changes in output data [23]. Polynomial and multiple nonlinear models are other types of regression models [24]. In the current study, a second order polynomial regression model and the general equation (1) may be changed to the following form for three factors and three levels:

$$
\begin{gathered}
Y=a_{0}+a_{1} x_{1}+a_{2} x_{2}+a_{3} x_{3}+a_{4} x_{1} x_{2}+a_{5} x_{1} x_{3}+a_{6} x_{2} x_{3}+a_{7} \\
x_{1}{ }^{2}+a_{8} x_{2}{ }^{2}+a_{9} x_{3}{ }^{2}
\end{gathered}
$$

where $\mathrm{x}_{1}$ is the laser power, $\mathrm{x}_{2}$ is the welding speed and $\mathrm{x}_{3}$ is the gap size and $\mathrm{a}_{0}$ to $\mathrm{a}_{9}$ are constants depending on laser power, welding speed and gap size. The target variable $\mathrm{Y}$ may stand for different geometry dimensions of the weld bead. In this work, penetration depth and weld bead width at the interface are modeled based on a second order polynomial regression model.

Penetration Depth The coefficient values of the penetration depth prediction are shown in Table 3. The coefficient values can be an indicator of the influence of each input parameter with respect to output variables, which is predicted in the regression model [25]. As it is shown the laser power and the gap size have a positive effect on penetration, however, the welding speed has a negative effect.

Table 3: Coefficients of regression model for penetration depth

\begin{tabular}{|c|c|c|c|c|}
\hline $\mathrm{a}_{0}$ & $\mathrm{a}_{1}$ & $\mathrm{a}_{2}$ & $\mathrm{a}_{3}$ & $\mathrm{a}_{4}$ \\
\hline-38.27 & 0.05 & -0.17 & 21.2 & 0 \\
\hline $\mathrm{a}_{5}$ & $\mathrm{a}_{6}$ & $\mathrm{a}_{7}$ & $\mathrm{a}_{8}$ & $\mathrm{a}_{9}$ \\
\hline-0.01 & 0.1 & 0 & 0.002 & -81.22 \\
\hline
\end{tabular}

The accuracy of the regression model can be determined through different methods [25] such as mean square error (MSE) and the F-test based on the analysis of variance (ANOVA). Analysis of variance is used to evaluate the performance precision of the model (results are shown in Table 4). DOF stands for degree of freedom, SS is sum of square, and MS is mean square. $\mathrm{F}_{0}$ is the mean square error divided by regression mean square. When $\mathrm{F}_{0}$ is larger, the precision of the regression model is better [24]. $\mathrm{F}(0.05)$ is the critical value of F-test for the significance level of $\% 95$. As it can be seen in Table $4, \mathrm{~F}_{0}$ is higher than $\mathrm{F}(0.05)$, which means that the results are significant and the relation between target (penetration depth) and independent variables (Laser power, speed and gap size) is well-formed [24]. 
Table 4: ANOVA of the regression model for estimation of penetration

\begin{tabular}{|c|c|c|c|c|c|}
\hline Factor & DOF & SS & MS & $\mathrm{F}_{0}$ & $\mathrm{~F}(0.05)$ \\
\hline Regression & 9 & 23.3 & 2.59 & 11.84 & 2.49 \\
\hline Residual & 17 & 3.7 & 0.21 & & \\
\hline Total & 26 & 27 & & & \\
\hline
\end{tabular}

Width at interface The coefficient values of the weld bead width at interface are shown in Table 5. It is shown that laser power and gap size have a positive effect and welding speed has a negative effect on the weld bead width at interface. As discussed earlier, increasing the welding speed decreases the heat input resulting in a smaller geometry of weld bead. Also, increasing the gap size results in a bulged weld bead and it implies that by increasing the gap size, the weld bead width at interface increases, which is in agreement with the regression model coefficients.

Table 5: Coefficients of regression model for weld bead width at interface

\begin{tabular}{|c|c|c|c|c|}
\hline $\mathrm{a}_{0}$ & $\mathrm{a}_{1}$ & $\mathrm{a}_{2}$ & $\mathrm{a}_{3}$ & $\mathrm{a}_{4}$ \\
\hline-20.54 & 0.03 & -0.08 & 4.57 & -3.09 \\
\hline $\mathrm{a}_{5}$ & $\mathrm{a}_{6}$ & $\mathrm{a}_{7}$ & $\mathrm{a}_{8}$ & $\mathrm{a}_{9}$ \\
\hline-0.002 & 0.11 & 0 & 0.001 & -30.35 \\
\hline
\end{tabular}

To evaluate the precision of the regression model used for the prediction of weld bead width at interface, an Ftest is performed. The results are shown in Table $6 . \mathrm{F}_{0}$ is higher than the $F(0.05)$, showing that the results are significant and the target (the weld bead width at interface) and independent variables relation is statically well defined.

Table 6: ANOVA of the regression model for estimation of weld bead width at interface

\begin{tabular}{|c|c|c|c|c|c|}
\hline Factor & DOF & SS & MS & $\mathrm{F}_{0}$ & $\mathrm{~F}(0.05)$ \\
\hline Regression & 9 & 5.64 & 0.62 & 10.92 & 2.49 \\
\hline Residual & 17 & 0.97 & 0.057 & & \\
\hline Total & 26 & 6.61 & & & \\
\hline
\end{tabular}

\section{Conclusions}

In the presented research, process parameters of laser welding for ZEK100 magnesium alloy is studied on weld quality and shape. The main conclusions are the followings:

(1) Better weld bead surface quality is achieved with low laser power, low welding speed, and less gap size.

(2) By increasing the laser power, penetration depth, and weld bead width at the interface is increased. Also by increasing the welding speed, penetration depth and weld bead depth is decreased.
(3) The regression model used in this study could establish a well defined relation between geometrical sizes of weld beads and process parameters

\section{Acknowledgement}

This work was funded by the NSF Grant No. IIP1034652 The authors acknowledge Andrew Socha, a research engineer at the Research Center for Advanced Manufacturing, for his assistance in performing the experiments.

\section{References}

[1] Liu, Liming (2010) Welding and joining of magnesium alloys, Woodhead Publishing.

[2] Haferkamp H., Von Alvensleben F., Burmester I. \& Niemeyer M. (1997) The characteristics of Laser Beam Welded Magnesium Alloys, ICALEO, San Diego, USA, 140-149.

[3] Kulekci, M.K. (2008) Magnesium and its alloys applications in automotive industry, The International Journal of Advanced Manufacturing Technology 39, 851-865.

[4] Mordike, B.L. \& Ebert, T. (2001) Magnesium properties-applications-potential, Materials Science and Engineering A302, 37-45.

[5] Forcellese, A., Gabrielli, F., \& Simoncini, M., (2012) Mechanical properties and microstructure of joints in AZ31 thin sheets obtained by friction stir welding using "pin" and "pinless" tool configurations, Materials and Design 34, 219-229.

[6] Braszczynska-Malik, K.N., \& Mróz, M., (2011) Gas-tungsten arc welding of AZ91 magnesium alloy, Journal of Alloys and Compounds 509, 9951-9958.

[7] Wahba, M., Mizutani, M., Kawahito, Y., \& Katayama, S., (2010) High-brightness disk laser welding of magnesium alloys, International Congress on Applications of Lasers \& Electro Optics, Anaheim, USA, 429-435.

[8] Luo, Y., Ye, H., Du, C., \& Xu, H., (2012) Influence of focusing thermal effect upon AZ91D magnesium alloy weld during vacuum electron beam welding, Vacuum 86, 1262-1267.

[9] Liu, L., Wang J., \& Song G., (2004) Hybrid laserTIG welding, laser beam welding and gas tungsten arc welding of AZ31B magnesium alloy, Materials Science and Engineering A381, 129-133. 
[10] Padmanaban, G., \& Balasubramanian, V., (2010) Optimization of laser beam welding process parameters to attain maximum tensile strength in AZ31B magnesium alloy, Optics \& Laser Technology $42,1253-1260$.

[11] Al-Kazzaz, H., Medraj, M., Cao, X., Jahazi, M., \& Xiao, M., (2005) Effect of welding speed on Nd:YAG laser weldability of ZE41A-T5 magnesium sand castings, $44^{\text {th }}$ annual conference of metallurgists of CIM, Calgary, Canada, 137-149.

[12] Abderrazak, K., Salem, W.B., Mhiri, H., Bournot, P., \& Autric, M., (2009) Nd:YAG Laser Welding of AZ91 Magnesium Alloy for Aerospace Industries., Metallurgical and Materials Transactions B40, 54-61.

[13] Hiraga, H., Inoue, T., Kamado, S., \& Kojima, Y., (2002) Effect of shielding gas and laser wavelength in laser welding magnesium alloy sheets, Welding International 16, 442-450.

[14] Pan, L.K., Wang, C.C., Hsiao, Y.C., \& Ho, K.C., (2004) Optimization of Nd:YAG laser welding onto magnesium alloy via Taguchi analysis, Optics \& Laser Technology 37, 33-42.

[15] Quan, Y.J., Chen, Z.H., Gong, X.S., \& Yu, Z.H., (2008) Effects of heat input on microstructure and tensile properties of laser welded magnesium alloy AZ31, Materials Characterization 59, 1491-1497.

[16] Bohlen, J., Nurnberg, M.R., Senn, J.W., Letzig, D., \& Agnew, S.R., (2007) The texture and anisotropy of magnesium-zinc-rare earth alloy sheets, Acta Materialia 55, 2101-2112.

[17] Gao, M., Mei, S., Wang, Z., Li, Z., \& Zeng, X., (2012) Process and joint characterizations of laserMIG hybrid welding of AZ31 magnesium alloy, Journal of Materials Processing Technology 212, 1338-1346.

[18] Cao, X., Jahazi, M., Immarigeon, J.P., \& Wallace, W., (2006) A review of laser welding techniques for magnesium alloys, Journal of Materials Processing Technology 171, 188-204.

[19] Lehner, C., Reinhart, G., \& Schaller, L., (1998) Welding of Die-Casted Magnesium Alloys on Production machines, Proceedings of ICALEO98, Orlando, USA, 18-27.

[20] Wang, Z., Gao, M., Tang, H., \& Zeng, X., (2011) Characterization of AZ31B wrought magnesium alloy joints welded by high power fiber laser, Materials Characterization 62, 943-951.
[21] Zhu, J., Li, L., \& Liu, Z., (2005) CO2 and diode laser welding of AZ31 magnesium alloy, Applied Surface Science 247, 300-306.

[22] Dhahri, M., Masse, J.E., Mathieu, J.F., Barreau, G., \& Autric, M., (2000) CO2 laser welding of magnesium alloys, Proceedings of SPIE, Munich, Germany, 725-732.

[23] Chatfield, C., (1988) Statistics for Technology, Chapman and Hall Press.

[24] Kim, T.W., \& Park, Y.W., (2011) Parameter Optimization Using a Regression Model and Fitness Function in Laser Welding of Aluminum Alloys for Car Bodies, International Journal of Precision Engineering and Manufacturing 12, 313-320.

[25] Montgomery, D.C., (2001) Design and analysis of experiments, John Wiley \& Sons Inc.

\section{Meet the Authors}

Masoud Harooni is a Ph.D. Candidate at the Research Center for Advanced Manufacturing (RCAM) at Southern Methodist University. He received his M.S. in Mechanical Engineering with a focus on hard-facing of carbon steel at Isfahan University of Technology, Iran in 2008. His current research includes laser welding of magnesium alloys, hybrid laser-arc welding, and laser welding of dissimilar alloys for the purpose of improved and optimized joining of light metals.

Fanrong Kong, Ph.D., is a research engineer at the Research Center for Advanced Manufacturing (RCAM) at Southern Methodist University. He received his Ph.D. in Mechanical Engineering with a focus on numerical modelling of laser welding at Southern Methodist University, in 2009. His current research includes heat transfer and laser material processing.

Blair Carlson, Ph.D., is a lab group manager at General Motors Research and Development in Warren, Michigan. He received his Ph.D. in Materials Science at University of Michigan. He has worked as an Advanced Manufacturing Manager at SAAB and as a Senior Engineer at General Motors. 
Radovan Kovacevic, Ph.D., is Herman Brown Chair Professor of Mechanical Engineering and the Director of Research Center for Advanced Manufacturing and Center for Laser-aided Manufacturing. He is a Fellow of the American Society of Mechanical Engineering, Society of Manufacturing Engineering, and American Society of Welding Engineering. He has to his credit over 500 technical publications and seven US Patents. 